Supporting Information

for

\title{
Control of Electrode-Molecule Interface for Molecular Devices
}

by

Kazumichi Yokota, Masateru Taniguchi, Tomoji Kawai

The Institute of Scientific and Industrial Research, Osaka University, 8-1 Mihogaoka, Ibaraki, Osaka 567-0047, Japan

taniguti@sanken.osaka-u.ac.jp 


\section{Preparation of monolayers}

To create a heat deposition gold film, we deposited gold $(99.95 \%$, Nilaco), heated with a tungsten

basket, onto a cleaved mica substrate at ultrahigh vacuum (base pressure: $5 \times 10^{-7} \mathrm{~Pa}$ ) while annealing it at about $450{ }^{\circ} \mathrm{C}$ with an $\mathrm{Si}$ heater. The surface structure of the heat deposition gold film was measured in the air with an STM. We observed a regular-triangle terrace that corresponded to the $\mathrm{Au}(111)$ plane. The terrace step height was $0.2 \mathrm{~nm}$, and the roughness of the terrace surface was about $0.1 \mathrm{~nm}$ or smaller over an area of several hundreds of $\mathrm{nm}$.

We dissolved benzenethiol $\left(\mathrm{C}_{6} \mathrm{H}_{5} \mathrm{SH}, 98 \%\right.$, Tokyo Chemical Industry), benzeneselenol $\left(\mathrm{C}_{6} \mathrm{H}_{5} \mathrm{SeH}\right.$, $95 \%$, Tokyo Chemical Industry), or biphenyl ditelluride $\left(\mathrm{C}_{6} \mathrm{H}_{5} \mathrm{TeTeC}_{6} \mathrm{H}_{5}\right.$, Tokyo Chemical Industry) in methanol $\left(\mathrm{CH}_{3} \mathrm{OH}, 99.93 \%\right.$, HPLC grade, Aldrich) to make $10 \mathrm{mM}, 10 \mathrm{mM}$, or $5 \mathrm{mM}$ solution respectively.

Benzeneselenol and biphenyl ditelluride are a highly toxic liquid and a solid respectively, with pungent odor at room temperature. We made these molecule solutions and monolayers inside a draft. However they lost the pungent odor once they were fixed on the gold substrates, which allowed us to handle them in the air. As mentioned in the text, the monolayers created from biphenyl ditelluride change to tellurium oxides. When the two molecules are oxidized with sodium hypochlorite until they lose their odor, they become harmless.

\section{$\underline{\text { XPS and UPS measurements }}$}

In the XPS measurement we used $\mathrm{Al} \mathrm{K \alpha}(1486.6 \mathrm{eV})$ as the X-ray source (XR3E2, VG), and a 100 
mm hemispherical electron energy analyzer (CLAM2, VG). In the UPS measurement, we used He I $(21.2 \mathrm{eV})$ as the UV-ray source (UVS300, Specs), and $150 \mathrm{~mm}$ hemispherical electron energy analyzer (PHOIBOS 150, Specs). The correction of the XPS measurement was done with the peak of $\mathrm{Au}\left(4 \mathrm{f}_{7 / 2}\right)$ at $84.0 \mathrm{eV}$. All measurements were performed in a vacuum condition under $2 \times 10^{-7} \mathrm{~Pa}$. 


\section{XPS spectrum of monolayers}
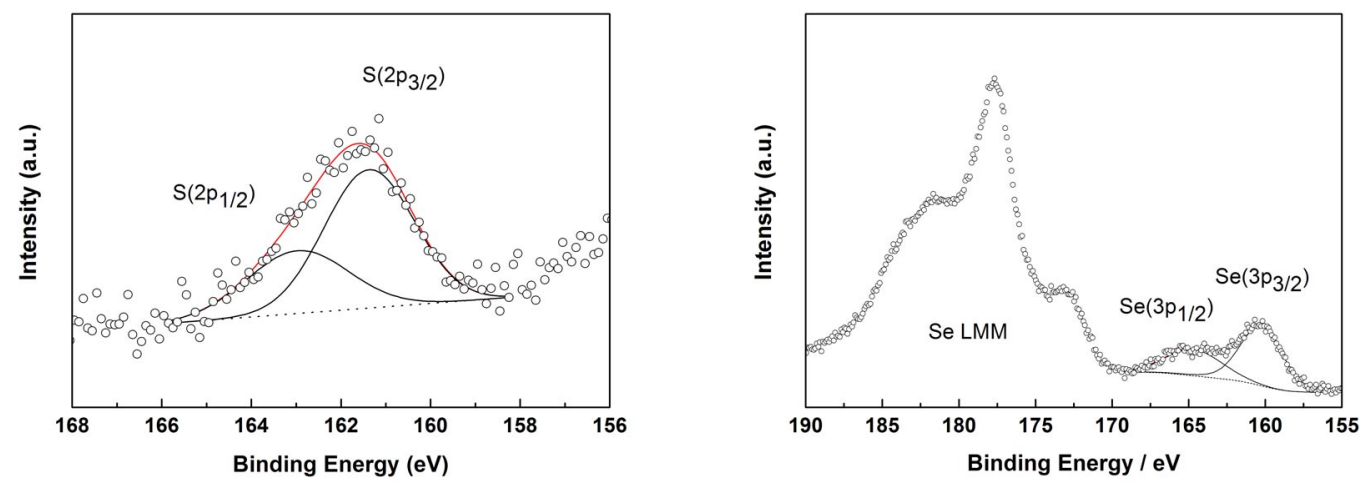

Figure 1S. XPS spectrum of the sulfur(2p) and selenium(3p) core levels from benzenethiol and benzeneselenol monolayers on $\mathrm{Au}(111)$. 